\title{
GUERRA Y PESTE EN ATENAS. REVISIÓN SOBRE EL POSIBLE ORIGEN DE LA EPIDEMIA ATENIENSE DE 430-426 A.C.
}

\author{
María del Pino Carreño Guerra \\ Hospital de Fuenlabrada \\ mcarre03@ucm.es \\ ORCID iD: https://orcid.org/0000-0002-4729-8911
}

Recibido: 2 enero 2018; Aprobado 18 octubre 2018.

Cómo citar este artículo/Citation: Carreño Guerra, María del Pino (2019), "Guerra y peste en Atenas. Revisión sobre el posible origen de la epidemia ateniense de 430-426 a.C.", Asclepio, 71(1): p249. https://doi.org/10.3989/asclepio.2019.01.

RESUMEN: La guerra del Peloponeso comenzó en el año 431 a.C. En el verano del segundo año los peloponesios invadieron el Ática, sus habitantes buscaron refugio dentro de las murallas de la ciudad y días después se desató una plaga en Atenas de mortalidad sin precedentes, que siguió activa ese año y el siguiente y volvió a irrumpir en 427 y 426 a.C. Durante cinco años, sucesivas oleadas de una epidemia aniquilaron aproximadamente un tercio de la población de la ciudad. La única fuente que nos relata la enfermedad es la obra de Tucídides, historiador ateniense coetáneo a los hechos, que describió la extensión y el impacto de la plaga en el segundo libro de su Historia de la Guerra del Peloponeso (47-52). El presente trabajo tiene como objetivo una revisión sobre las distintas teorías médicas propuestas como causa de esta epidemia, con la cautela metodológica que requiere el abordaje de una enfermedad que ocurrió hace más de 2500 años.

PALABRAS-CLAVE: Atenas, guerra del Peloponeso, epidemia, clínica, epidemiología.

\section{WAR AND PLAGUE IN ATHENS. REVIEW OF THE POSSIBLE ORIGIN OF THE ATHENIAN EPIDEMIC OF 430-426 BC}

\begin{abstract}
The Peloponnesian War began in the year 431 BC. In the summer of the second year, the Peloponnese attacked the Attic Peninsula, and its inhabitants sought refuge inside the city walls of Athens. Days later, an unprecedentedly deadly plague spread throughout the city. The plague rampaged the city for the rest of the year and the following one, and made reappearances in both 427 and 426 BC. During five years, successive waves of the epidemic annihilated almost a third of the city's population. The only source describing this outbreak is the work by Thucydides, an Athenian historian who lived through the epidemic, and who described the extent and impact of the plague in his second book of the History of the Peloponnesian War (47-52). The objective of this journal article is to review, with the methodological caution required to approach an illness that occurred more than 2500 years ago, the various medical theories proposed as the cause of this epidemic.
\end{abstract}

KEY WORDS: Athens, Peloponnesian War, epidemic, clinical, epidemiology. 


\section{INTRODUCCIÓN}

La guerra del Peloponeso comenzó en el año 431 a.C. y enfrentó a las dos grandes potencias griegas del momento, Atenas y Esparta ${ }^{1}$. En el verano del segundo año los peloponesios invadieron el Ática, sus habitantes buscaron refugio dentro de las murallas de la ciudad y días después se desató una plaga en Atenas de mortalidad sin precedentes, que siguió activa ese año y el siguiente y volvió a irrumpir en 427 y 426 a.C. (Th.1,1) Durante cinco años, sucesivas oleadas de una epidemia aniquilaron aproximadamente a un tercio de la población ateniense (Th.2,52). La única fuente contemporánea a los hechos que nos relata la enfermedad es la obra del historiador ateniense Tucídides, Historia de la guerra del Peloponeso. Sobre todo, echamos de menos alguna referencia a la peste en los escritos hipocráticos, aunque somos conscientes de que pudo existir y quizá se perdiera.

Tucídides realizó una descripción cuidadosa y detallada de los signos y síntomas de la enfermedad, muy poco habitual en la época salvo en los citados escritos hipocráticos. Sin embargo, hay que recordar que en la Antigüedad no estaban separadas las disciplinas como hoy en día, por lo que encontramos temas médicos en escritos de estudiosos de disciplinas alejadas de la medicina como Heródoto, Platón o Aristóteles ${ }^{2}$. De hecho, como afirma Nutton (2004, p.73), en la Antigüedad ni siquiera se podía establecer una división clara entre médicos y filósofos en términos de nivel de abstracción de sus teorías, pues todos prestaban mucha atención a los fenómenos naturales.

El relato de Tucídides sobre la peste describe al mismo tiempo la enfermedad física y la enfermedad moral de la ciudad, pues enfatiza el impacto de la guerra y el colapso moral que ésta ocasionó en la población de Atenas ${ }^{3}$. Lo anterior queda acentuado por la colocación de la descripción de la peste casi inmediatamente después del discurso fúnebre en el que Pericles realiza una loa a la democracia ateniense. Así, frente al orden y la armonía de la Atenas democrática, se alzó el caos y la desintegración de la polis durante la epidemia.

Para Rechenauer (2011, p. 243), el relato de la peste no se trata de un pasaje aislado con información médica, sino que está ligado de una manera orgánica con el resto de la composición sobre la guerra del Peloponeso. Para este autor, la enfermedad física de la población presagia el declive del poder ateniense, que podría entenderse como la enfermedad de un organismo político. Tucídides describe el proceso por el cual la violencia social y política socava la razón, con la peste como catalizador que aceleró el proceso.

Debido al contagio, la peste fue asunto de toda la población, y no sólo de unos pocos, por lo que la destrucción del orden abarcó todas las facetas de la vida en la polis, de tal forma que podría hablarse del colapso de una sociedad como consecuencia del proceso de infección. Tucídides utiliza el motivo de la violencia aniquiladora de la enfermedad para conectar la epidemia con su tema político principal, la guerra.

Quiero justificar el empleo del sustantivo "peste" en el título y el desarrollo del trabajo a pesar de su incorrección desde el punto de vista médico ${ }^{4}$. Según el diccionario de la RAE el término peste puede aludir a cualquier enfermedad que cause gran mortandad ${ }^{5}$ y éste es el sentido en que se utilizó durante toda la Antigüedad. Por otra parte, el término peste también puede aludir a una corrupción en las costumbres ${ }^{6}$, lo que va muy en consonancia con una interpretación metafórica del relato de Tucídides sobre la epidemia ${ }^{7}$.

Ambas interpretaciones, real y metafórica, pueden coexistir. De hecho, aunque una lectura metafórica no invalide una interpretación científica de los hechos, muchos autores ${ }^{8}$ se han basado en ella para afirmar que la peste de Atenas nunca existió y que cuando el historiógrafo ateniense describe los signos y síntomas de la epidemia, en realidad se estaba refiriendo a la enfermedad moral que asoló Atenas en los primeros años de la guerra del Peloponeso. Sin embargo, con el descubrimiento de una fosa común en el Cerámico de Atenas en la que los cuerpos estaban colocados sin ningún orden y las ofrendas eran muy escasas como si hubiera habido que enterrar muchos cuerpos en poco tiempo, la plausibilidad de una epidemia ateniense ha cobrado fuerza, sobre todo al datar estos restos óseos en 429-427 a.C. (Baziotopoulou-Valavani, 2002).

A lo largo del tiempo, el relato del historiador ateniense sobre la epidemia de Atenas ha supuesto un modelo de referencia fundamental para todo el que ha querido describir el horror de la peste. La doble vertiente física y social de su descripción de la enfermedad ha sido fuente de inspiración para numerosas obras de autores tanto de la Antigüedad ${ }^{9}$, como del 
Medievo $^{10}$, y modernos ${ }^{11}$. Sí es verdad que en los primeros la peste solía constituir una enfermedad física que afectaba a una población, mientras que en los últimos la peste se utilizaba más bien en su sentido metafórico de descomposición social.

\section{JUSTIFICACIÓN DEL TRABAJO Y MÉTODO}

El presente trabajo tiene como objetivo profundizar en la epidemia ateniense a partir de la descripción que Tucídides hace de ella. He realizado un abordaje médico de dicha "peste", en el cual he sistematizado las distintas teorías sobre su posible etiología desde un enfoque clínico y desde un enfoque epidemiológico. Soy consciente de la controversia que existe sobre la pertinencia de los diagnósticos retrospectivos, por lo que no pretendo deshacer el nudo gordiano, ni cortarlo dándole un enfoque diferente como hace Cunningham (2002, p. 13), y acertar con el diagnóstico microbiológico de una epidemia que ocurrió hace 2500 años. Pretendo un abordaje historiográfico para examinar las distintas tesis que se han defendido en distintas épocas y la pertinencia de éstas a la luz de los nuevos conocimientos.

A la hora de tratar de identificar una enfermedad del pasado nos encontramos antes dos desafíos distintos, aunque estrechamente relacionados. Por un lado, el ontológico, que nos hace dudar sobre la persistencia de una enfermedad a lo largo del tiempo y, por otro, el epistémico que habla sobre la imposibilidad de acceder a la verificación científica de un diagnóstico del pasado (Muramoto, 2014, p. 1).

Estoy de acuerdo con Cunningham (2002, p. 13) en la duda ontológica sobre la plausibilidad de la identificación de las enfermedades del pasado. La cuestión que no comparto con el citado autor británico es que nuestro concepto microbiólogico de la infección $y$, por tanto, la diferente visión que tenemos sobre la enfermedad, impida el acercamiento a las infecciones de la era premicrobiológica. En mi opinión, sí podemos acercarnos a ellas, siendo conscientes de la complejidad conceptual y metodológica que ello implica y siempre que tengamos presente que existen dos conceptos diferentes: por un lado, la taxonomía de las enfermedades y por otro, el acto de diagnosticar a un paciente.

En cuanto al segundo, no olvidemos que las categorías diagnósticas son una construcción humana y no una entidad biológica. Como afirma Cunningham
(2002, p. 17), el concepto de enfermedad no existe independiente del acto del diagnóstico, el cual no deja de ser una práctica social cambiante con el tiempo y el lugar. Además, siguiendo a Muramoto (2014, p. 6), el diagnóstico médico no es un juicio apodíctico sino probabilístico. Dado que la epidemia de Atenas fue una enfermedad infecciosa, nunca podremos afirmar que se trataba de una enfermedad concreta, es decir, emitir un diagnóstico preciso, pues nos falta la herramienta fundamental, el laboratorio ${ }^{12}$. Sin embargo, sí podremos hacer un juicio clínico sindrómico a partir de los signos y síntomas descritos por Tucídides, como se hace muy habitualmente en la práctica clínica $^{13}$. Coincido con Muramoto $(2014$, p. 8 ) en que los diagnósticos retrospectivos deben ser siempre sindrómicos, plausibles y coherentes con el contexto descrito en la fuente de información.

Sobre la pertinencia de que un historiador utilice construcciones modernas para analizar el pasado hay mucha literatura, pero ningún principio universalmente aceptado. No considero una práctica criticable mirar al pasado desde nuestro presente para intentar entenderlo mejor, no lo supongo un anacronismo sino una construcción artificial para mejorar nuestra comprensión del mundo de ayer. Por tanto, no considero erróneo examinar las tesis emitidas sobre si los signos y síntomas que describe Tucídides podrían corresponder a alguna entidad nosológica infecciosa actual sin el ánimo de emitir afirmaciones categóricas sobre la etiología de dicha epidemia.

Cunningham afirma (2002, p.15) que los estudiosos suelen asumir la continuidad de las enfermedades del pasado con las actuales y que, sin embargo, la vivencia de la enfermedad es distinta en cada época y en cada lugar pues se trata de un fenómeno social. Coincido con él, con Arrizabalaga (2002, p. 57) y con Wilson (2000, p.273), en que la enfermedad no es sólo una realidad biológica sino, sobre todo, una construcción humana inserta en un contexto histórico y con unas condiciones socioculturales determinadas. Sin embargo, no creo que lo anterior invalide todo diagnóstico retrospectivo, incluso aquél en el que se asuma el manejo cauto de los conceptos y la complejidad metodológica. Si no aceptáramos tal premisa, algunas disciplinas, como por ejemplo la paleopatología, carecerían de sentido. Arrizabalaga (1999, p.258) aboga por lo estudios interdisciplinares que aporten riqueza a la investigación, en los que las ciencias modernas contribuyan con un enfoque complementario a los estudios de humanidades. 


\section{DESCRIPCIÓN DE LA EPIDEMIA}

Según Tucídides (2.48), la plaga se originó en Etiopía, desde donde se expandió a Egipto, Libia y parte del imperio persa. Atacó la isla de Lemnos y otros lugares antes de penetrar por el puerto del Pireo, y desde allí se extendió por toda la ciudad. Tucídides (2.17.1-2) en su relato no especula sobre la causa de la enfermedad, pero en ningún momento la supone efecto de deidades ofendidas ${ }^{14}$. Se transmitía de persona a persona y los médicos y los cuidadores eran víctimas habituales de la enfermedad $(2.47 .4)^{15}$. La perspicacia del historiador va más allá pues, en otro párrafo (2.51.6), señala que los enfermos que sobrevivían no volvían a enfermar, con lo cual, sin saberlo (ya que sólo lo observó y no entendió la fisiología), enunció las bases de la inmunidad adquirida ${ }^{16}$.

Tucídides (2.52.1) también señaló con acierto en su descripción de la epidemia que la sobrepoblación de la ciudad fue un factor que contribuyó a su virulencia. Existen otras dos fuentes antiguas ${ }^{17}$, si bien mucho más tardías que Tucídides que, en su relato de la peste de Atenas también defendieron el hacinamiento como causa y factor agravante de la plaga. De hecho, el historiador ateniense señaló (2.52.2) que los individuos que llegaban a la ciudad eran los que sufrían especialmente los efectos de la plaga, sobre todo por las pésimas condiciones de vida que sufrían. Kosak (2000, p.50) apunta que quizá su relato contribuyera a que desde finales del siglo $\mathrm{V}$ a.C. los atenienses comenzaran a percibir la ciudad física como un lugar potencialmente peligroso y ya no un lugar de refugio y protección como hasta entonces, como se aprecia en algunos pasajes de Tucídides (por ejemplo, en Th.2,61).

La descripción que realiza Tucídides de los signos y síntomas de la enfermedad es muy cuidadosa. En ella se comprueba que el historiador ha adaptado los principios y métodos de la medicina pragmática a su interpretación de la historia y su relato sobre la peste. Las historias clínicas hipocráticas muestran una gran pulcritud en la observación así como una rigurosa ordenación cronológica de los síntomas ${ }^{18}$. En ellas no se encuentra un diagnóstico en la forma en que hoy día se concibe, ya que para Hipócrates diagnosticar consistía en saber ordenar los procesos morbosos individuales en la regularidad general de la naturaleza y no en adscribir el caso clínico observado a la entidad nosológica a la que pertenece, como se hace hoy en día ${ }^{19}$ (Laín Entralgo, 1949, p.31).
Según Laín Entralgo (1949, p.32), para los médicos hipocráticos diagnosticar consistía en entender científicamente al enfermo y no en saber catalogarlo según su modo de enfermar. Lo cual no implica que el interés de Hipócrates dirigido hacia el conocimiento de la individualidad del enfermo excluyese toda consideración tipificadora del enfermar de sus pacientes $^{20}$.

Por otra parte, era característico de los médicos hipocráticos incidir en el pronóstico de las enfermedades, en el curso natural de éstas. Conocer técnicamente un caso clínico, es decir diagnosticar, consistía entre otras cosas, en saber con mayor o menor certeza cuál iba a ser la suerte del enfermo ${ }^{21}$ (Laín Entralgo, 1970, p.238). Horstmanshoff (1990, p.180) afirma acertadamente que era el establecimiento del pronóstico lo que distinguía el saber médico del mero empirismo ${ }^{22}$. El pronóstico informaba al paciente del curso clínico de su enfermedad, de la situación presente y de lo que le ocurriría en el futuro. Era esta habilidad de los médicos la que los acercaba a la retórica y a la ciencia y los alejaba de la artesanía.

Así, siguiendo el planteamiento médico, Tucídides comenzó describiendo brevemente las condiciones generales que precedieron al brote epidémico. Después, detalló los signos y síntomas observados sin hacer comentario alguno sobre éstos ni sobre eventuales terapias. A continuación, señaló los días en los que era previsible que la enfermedad hiciera "crisis": el séptimo y el noveno, y concluyó con una relación de las complicaciones que ocurrían a los enfermos que sobrevivían.

Se distinguen así cuatro periodos en la descripción del historiador: un primer periodo que corresponde con el periodo de incubación, que fue muy corto, con un comienzo súbito; una segunda fase de siete o nueve días en la que el enfermo desarrollaba los principales signos clínicos, y que puede dividirse a su vez en dos secciones: la primera que refleja el orden en el que aparecieron los principales signos y síntomas (calor en la cabeza, inflamación de los ojos, hiperemia de faringe y lengua, halitosis, estornudos y ronquera, tos, dolor en el pecho, vómitos y convulsiones) y la segunda que relata los fenómenos que aparecieron en este periodo (eritema en piel, vesículas y úlceras, sensación de calor, sed intensa, insomnio y decaimiento); un tercer periodo tras el noveno día, en el que los pacientes que sobrevivían sufrían problemas intestinales, diarrea y debilidad que terminaba en ocasiones con la muerte; y por último, una fase de 
complicaciones tardías, entre las que se describen gangrena de las zonas acras, pérdida de visión y amnesia ${ }^{23}$.

Un apunte tucidídeo (2.52.1) que demuestra sus dotes de observación es la frase en la que refiere que no coexistieron otras enfermedades durante la epidemia ${ }^{24}$. Tan de cerca pudo estudiar la enfermedad que el propio historiador la padeció (2.48) y sobrevivió a ella. Que el propio Tucídides padeciera la dolencia, según Longrigg (1980, p.209), debió introducir un sesgo de subjetividad en su relato, pues pudo dar más importancia a sus síntomas, que quizá no eran los de la mayoría. Por otra parte, que él sobreviviera, aparentemente sin secuelas, pudiera indicar que su enfermedad no era el prototipo de infección padecida por las víctimas de la epidemia.

Existen tres posibilidades a la hora de intentar diagnosticar la enfermedad que describió Tucídides: un abordaje clínico, uno epidemiológico y uno paleopatológico. El más objetivo pero también el más complicado de realizar es el último. Sin embargo, el hallazgo, ya comentado, en 1994-95 de una fosa común en la zona del Cerámico de Atenas que contenía restos óseos procedentes de unos ciento cincuenta cuerpos, permitió al equipo de Papagrigorakis realizar un análisis de la pulpa dentaria ${ }^{25}$ de varias piezas dentales para buscar material genético de algún microorganismo. El estudio permitió identificar secuencias de ADN muy similares a las de Salmonella enterica serotipo Typhi en la pulpa de tres piezas dentales. Ello les llevó a concluir que la fiebre tifoidea, causada por dicha bacteria, pudo estar implicada en la epidemia ateniense. Varios de los signos y síntomas de la fiebre tifoidea coinciden con los descritos por Tucídides, especialmente la fiebre y la clínica gastrointestinal, sin embargo, muchos otros no lo hacen, lo que Papagriorakis, Yapijakis et al (2006, p.213) explican como posiblemente debido a variaciones genómicas entre las bacterias que podrían explicar las diferencias en la sintomatología, aunque no descartan que la epidemia pudiera deberse a varias infecciones concurrentes.

\section{POSIBLES ETIOLOGÍAS DE LA PESTE SEGÚN LOS SIGNOS Y SÍNTOMAS CLÍNICOS}

Es importante conocer que la percepción antigua y las descripciones sobre enfermedades, así como su clasificación, son muchas veces imposibles de correlacionar con las enfermedades registradas en un texto médico moderno (Nutton, 2004, p.22). Como ya he comentado, los médicos hipocráticos daban nombre a pocas entidades nosológicas y preferían describirlas por sus signos y síntomas. Como afirman Hope y Marshall (2000, p.24), dado el desarrollo de la teoría médica de la época, uno esperaría encontrar algún grado de correspondencia entre la realidad médica y la imagen médica. Sin embargo, no es así y la imaginería médica antigua era completamente distinta a la moderna.

En el último siglo se han realizado más de doscientos estudios sobre la posible etiología de la enfermedad descrita por Tucídides. Estos estudios han sido abordados por filólogos clásicos, historiadores y médicos. Los primeros están limitados por su falta de conocimientos médicos y los últimos por su desconocimiento del griego clásico, por lo que, en muchas ocasiones, las traducciones no concuerdan con ningún signo clínico. Por fin, los tres tipos de estudiosos están limitados porque trabajan sobre términos y conceptos de salud y enfermedad de hace más de dos milenios.

Otro factor que añade dificultades al intento de tipificación de la enfermedad tucidídea es el hecho de que los signos clínicos suelen ser muy parecidos en los primeros estadios de muchas enfermedades infecciosas. En realidad, los signos y síntomas descritos por Tucídides no concuerdan totalmente con ninguna entidad nosológica que exista actualmente. De hecho, él mismo (2.47.4) apunta al inicio de la descripción que nunca se había visto una enfermedad parecida a la que él describe.

Con todas las limitaciones apuntadas, Durack, Littman et al (2000, p.393) desarrollan un esquema en el que apuntan seis posibilidades diagnósticas para la epidemia descrita por Tucídides: una enfermedad infecciosa conocida (ántrax, peste bubónica, cólera, dengue, virus Ébola, erisipela, muermo, fiebre Lassa, malaria, sarampión, meningitis, fiebre del valle del Rift, escarlatina, viruela, síndrome del shock tóxico, tularemia, fiebre tifoidea o tifus epidémico); una enfermedad infecciosa conocida pero que hubiera sido más virulenta por haber afectado a una población virgen; una enfermedad conocida no infecciosa (ergotismo, aleukia tóxica alimentaria o escorbuto); dos enfermedades simultáneas (gripe complicada con síndrome de Guillain-Barré, gripe complicada con síndrome del shock tóxico, tifus epidémico y peste bubónica, tifus epidémico y disentería, tifus epidémi- 
co y fiebre amarilla o tifus epidémico y escorbuto); una enfermedad que haya cambiado su curso clínico y sea irreconocible para nosotros; y, por último, una enfermedad que no exista en la actualidad.

A continuación, quería apuntar brevemente las razones a favor y en contra de cada una de las posibilidades anteriores. En primer lugar, voy a referirme a las enfermedades no infecciosas, entre las que encontramos el ergotismo. Esta es una enfermedad que resulta de la ingesta de centeno $u$ otros cereales contaminados por el hongo Claviceps purpurea. Aunque el centeno no era un cereal que se consumiera habitualmente en Atenas, quizá la situación bélica propició que se importara éste desde Tracia por la extrema necesidad que existía en el Ática tras la invasión peloponesia $^{26}$ (Longrigg, 1980, p.217). Sin embargo, también se importaban cereales de Rusia, Egipto y Sicilia, por lo que es poco probable que enfermara un porcentaje tan alto de la población, así como que se afectaran por igual ricos y pobres. Otro factor que no concuerda con el ergotismo es que las tropas de Potidea no se vieran afectadas hasta la llegada de los refuerzos provenientes de Atenas (Th., 2.57.2). Por otra parte, que Etiopía, Egipto, Libia y parte del imperio persa se vieran afectados por la enfermedad concuerda más con que la dolencia fuera infecciosa ${ }^{27}$. La misma razón se puede dar para considerar poco probable la aleukia tóxica alimentaria, de patogenia similar.

El escorbuto, otra enfermedad no infecciosa, es la dolencia resultante de la deficiencia de vitamina $C$ por la escasa ingesta de frutas y verduras frescas. Era frecuente que apareciera durante épocas de hambruna, en largos viajes transatlánticos o tras duros inviernos septentrionales. No sería extraño que se hubieran producido deficiencias de distintas vitaminas durante el asedio de la ciudad, y que el escorbuto pudiera haber empeorado los síntomas de la enfermedad que causó la epidemia fuera ésta la que fuere. Así, las razones aducidas en el párrafo anterior permiten excluir el escorbuto como causa primera de la enfermedad, aunque no como factor agravante de la misma.

Así pues, parece claro que debió ser una enfermedad infecciosa. Pudo tratarse de una infección no especialmente virulenta que se agravara por afectar a una población nunca expuesta al agente microbiano. Durack, Littman et al (2000, p.393) y Leven (2004, p.368) nos recuerdan que existen ejemplos muy bien documentados de ello 28 . Otra posibilidad apuntada por Durack, Littman et al es la de que no podamos identificar la infección responsable de la epidemia de Atenas porque el microorganismo causante de la infección haya perdido virulencia con el paso del tiem$p^{29}$ y se haya convertido en un agente causante de una patología más benigna.

Otra opción es que la enfermedad ya no exista porque se haya erradicado sin que el hombre tomara ninguna medida ${ }^{30}$. Y por último, es posible que la epidemia ateniense estuviera causada por dos enfermedades que actuaran simultáneamente o bien una como complicación de la otra ${ }^{31}$. Esta última posibilidad tiene poco sentido desde el punto de vista médico. Es cierto que un paciente puede complicarse por la coexistencia de varias enfermedades, pero resulta una opción poco plausible para toda una ciudad.

Tras desechar las opciones anteriores, coincido con Durack, Littman et al (2000, p.394) en que lo más útil para realizar el diagnóstico diferencial de la enfermedad que nos describe Tucídides es focalizar nuestra atención sólo en la información que conocemos con certeza y arrinconar de momento los hallazgos cuestionables. Así, nuestras certezas sobre la epidemia ateniense son: que existió un brote de una enfermedad infecciosa en una situación de guerra, hambre y hacinamiento; que la epidemia se prolongó durante varios años, con una incidencia fluctuante a lo largo de ellos; que los pacientes presentaron un exantema (sobre este tema volveré más adelante); que algunos pacientes desarrollaron síntomas respiratorios y gastrointestinales; que la tasa de mortalidad de dicha infección fue de alrededor del 25\%; que la muerte ocurría habitualmente al séptimo o noveno día de evolución; y que algunos de los pacientes que sobrevivieron desarrollaron complicaciones extrañas, como gangrena periférica, ceguera o amnesia.

Con el esquema anterior en mente, podemos desechar algunas de las etiologías que se han barajado como posible causa de la enfermedad ateniense, en primer lugar, la peste bubónica. Además de que el cuadro clínico de la infección por Yersinia pestis difiere en muchos aspectos del descrito por Tucídides, existe un signo patognomónico de ésta, los bubones, que no aparece en la descripción tucidídea. Algunos autores han argumentado que quizás el historiador olvidó mencionar los bubones, pero parece un olvido demasiado importante como para obviarlo. Por otra parte, desconocemos si la rata era endémica de Atenas ${ }^{32}$. 
Uno de los puntos clave del relato tucidídeo es el del exantema. Las manifestaciones cutáneas que des-

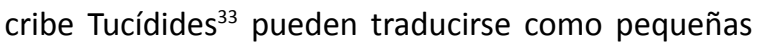
flictenas y úlceras (Romilly, 1991, p.36). Durack, Littman et al $(2000,392)$ opinan que la traducción vesículas y pápulas sería más correcta y aportaría un matiz diferente. No opino como Durack, Littman et al pues, aunque el primer término se podría traducir efectivamente por vesículas, tenemos una traducción más directa y exacta, "flictenas". En cuanto al segundo término, creo que en ningún caso podría traducirse por pápulas, sino efectivamente por "úlceras".

En este caso concreto, la exactitud en la traducción resulta fundamental pues que la erupción cutánea fuera maculosa, papulosa, vesicular, pustulosa o hemorrágica resultaría en diagnósticos completamente distintos. Un exantema maculo concordaría con una fiebre tifoidea ${ }^{34}$, uno papuloso concordaría con un sarampión ${ }^{35}$, uno vesículo-pustuloso con la viruela y uno hemorrágico con la infección por virus Ébola ${ }^{36}$. Por otra parte, apunta Littman (1969, p.268) que se echa de menos más rigor clínico en la descripción del exantema. Tucídides no nos informa sobre su duración, sobre sus estadios evolutivos, ni sobre cómo se resolvió.

Entre las enfermedades infecciosas, una de las primeras que nos viene a la mente es la infección por el virus Influenza, que frecuentemente cursa en brotes y que ha causado una gran mortalidad a lo largo de la historia. Es una infección con una tasa de contagio altísima, con un curso clínico parecido al que narra Tucídides (aunque no exacto), pero que tiene una tasa de mortalidad mucho menor que la de la infección ateniense ${ }^{37}$. Otro dato que va en contra del virus de la gripe, que desarrollaré más extensamente en el apartado siguiente, es que las epidemias de gripe afectan muy rápidamente a zonas muy extensas pero se extinguen igual de rápido en unas pocas semanas, al contrario que la epidemia ateniense que cursó de manera ininterrumpida o en largos brotes recurrentes a lo largo de cinco años ${ }^{38}$ (Morens, Littman, 1992, p.276).

En cuanto al virus de la viruela, es un agente con el que muchos autores están de acuerdo que pudo ser el causante de la epidemia, especialmente por el ya mencionado asunto del exantema. Tucídides (2.49.2) describe la piel de los afectados como "enrojecida y lívida" y con vesículas y úlceras, lo que se corresponde con la típica erupción varioliforme (Littman, 1969, p.268). El mismo autor asegura que la distribución de las lesiones cutáneas también coincide, así como que la viruela podía causar ceguera ${ }^{39}$ como complicación tardía. Sin embargo, Tucídides no describe la postración, la cefalea y la lumbalgia, que son tan características de la viruela.

Por otra parte, existe un dato clave de la viruela que falta en el relato tucidídeo: las marcas indelebles que quedaban en toda la superficie cutánea y especialmente en la cara. No parece posible que se debiera a un "olvido" del historiador, pues si él mismo padeció la enfermedad, las cicatrices debieron desfigurarle el rostro ${ }^{40}$. Littman $(1969$, p.271) sugiere la posibilidad de que lo anterior no se debiera a un olvido sino a una omisión deliberada y que, siguiendo la metodología de los textos hipocráticos, el historiador quisiera establecer el pronóstico de la enfermedad, señalando los estadios clínicos de ésta. Así, señaló el exantema pero no las cicatrices que éste dejó en la piel de los afectados. Longrigg (1980, p.221) por su parte, señala que el apunte de Littman no le convence, pues el ánimo de Tucídides al describir la enfermedad (2.48.3) fue que si volvía a aparecer pudiera ser reconocida con facilidad.

Otra posibilidad infecciosa como causante de la epidemia de Atenas es el tifus epidémico, causado por la bacteria intracelular Rickettsia prowazekii, de la que el ser humano se considera el único o principal reservorio. La enfermedad es más frecuentemente en invierno y en primavera. Los vectores de la enfermedad son los piojos, por lo que esta enfermedad se ha asociado tradicionalmente con situaciones de pobreza, hambruna, guerra y hacinamiento que favorecen su proliferación ${ }^{41}$. El piojo corporal humano se infecta al alimentarse de la sangre de las personas enfermas. Las rickettsias ingeridas por el piojo infectan las células epiteliales del intestino del piojo, éste las excreta por las heces y así pueden introducirse en huéspedes humanos susceptibles a través de pequeñas heridas o escoriaciones de la piel, o incluso por vía respiratoria por la aerosolización de las heces secas del piojo (Kliegman, Behrman et al 2009, p.1297).

Las manifestaciones clínicas del tifus epidémico ${ }^{42}$ coinciden en muchos aspectos con las descritas por Tucídides, así como las complicaciones. En lo que no coinciden exactamente ambas afecciones es en el exantema. El del tifus comienza siendo maculoso y evanescente para evolucionar hacia petequial y purpúrico, pero nunca vesiculoso (Kliegman, Behrman et al, 2009, p.1298). Otros datos que no concuerdan son las manifestaciones gastrointestinales, habitualmente 
ausentes en el tifus, así como que la duración clínica de esta infección suele ser bastante más larga que la de la enfermedad tucidídea ${ }^{43}$.

\section{UNA APROXIMACIÓN MÁS ACERTADA: POSIBLE ETIOLOGÍA DE LA PESTE SEGÚN DATOS EPIDEMIOLÓGICOS}

Existen varios datos epidemiológicos que pueden extraerse del relato de Tucídides que merece la pena reseñar por su importancia a la hora de intentar establecer un diagnóstico. En primer lugar, Tucídides (2.54.1) nos relata que las tropas enemigas que asediaban la ciudad no se vieron afectadas por la enfermedad y que ésta quedó circunscrita a las murallas. La enfermedad afectaba a los que llegaban para refugiarse dentro de su perímetro y se extendió por fuera de éste cuando las tropas atenienses fueron a reforzar el asedio de Potidea ${ }^{44}$. Atacó principalmente a los que cuidaban de los enfermos, sin diferenciar a ricos o a pobres, y lo hizo en todas las estaciones del año, pues si bien la primera oleada ocurrió en verano, continuaron existiendo casos en un nivel endémico en los dos años siguientes y volvió a producirse un nuevo brote en 426 a.C. (Th. 3.87.3).

El verano en el que comenzó la epidemia, la ciudad de Atenas albergó a una cantidad inmensa de refugiados que acudían de toda el área del Ática invadida por el ejército peloponesio. Distintas estimaciones realizadas a partir de los datos demográficos de que disponemos sugieren una cifra de población que varía entre 250.000 hasta 400.000 que se hacinó en Atenas en aproximadamente $5.2 \mathrm{~km}^{2}$. Esta densidad de población es altísima ${ }^{45}$ y debió favorecer la proliferación de roedores e insectos. Sí es cierto que, en los años siguientes en los que la enfermedad continuó vigente, la densidad de población de la ciudad debió ser mucho menor, pues muchos de los campesinos volvieron a sus tierras.

Otro detalle epidemiológico importante es que los perros y los pájaros de presa enfermaban tras alimentarse de los cadáveres (Th. 2.50). La posible transmisión de la enfermedad a animales de presa sugiere una zoonosis, aunque algunos autores consideran que la referencia que hace Tucídides a ello es tan vaga que no permite extraer conclusiones firmes (Retief, Cilliers, 1998, p.52). Es más, Littman (1969, p.267) apunta que Tucídides no dice exactamente que la enfermedad se propagara a los animales, sino que éstos y las aves carroñeras evitaban los cadáveres diseminados por la ciudad y que los que se alimentaban de ellos, morían.

Con la densidad de población anteriormente estimada, la tasa de ataque ${ }^{46}$ de la enfermedad fue de $25-100 \%$ y la tasa de mortalidad ${ }^{47}$ de aproximadamente un $25 \%$. Estas cifras las extraen Morens y Littman (1992, p.277) del dato que aporta Tucídides (2.58.3) sobre las tropas de refuerzo atenienses que acudieron al asedio de Potidea, 4000 hoplitas de los que murieron 1050. En este caso, el historiador sólo menciona la muerte de los soldados, pero podemos estimar que la de los ciudadanos debió ser similar. Más adelante, el historiador apunta (3.87.3) que no existió nada que debilitara las fuerzas atenienses como la peste, ya que entre los hoplitas alistados "murieron no menos de cuatro mil cuatrocientos hombres y trescientos jinetes, a más de un número incalculable de otras bajas". Morens y Littman (1992, p.277) sugieren que el $78 \%$ de las 4400 muertes de hoplitas debieron ocurrir en el primer brote de la enfermedad. Diodoro de Sicilia (XII, 58, 4), siglos después, apuntó que en la peste de Atenas murió un tercio de su población.

Para intentar afinar el diagnóstico, Morens y Littman (1992, p.283) comparan en su estudio tres posibles modos de transmisión de la epidemia ateniense: a partir de una fuente común, de persona a persona o asociada a un reservorio. En primer lugar, comentan la posibilidad de que los atenienses adquirieran la enfermedad a partir de una fuente común, ya fuera el agua, ya algún alimento. En cuanto al agua, la epidemia comenzó en el Pireo, un puerto cuyas cisternas no estaban conectadas con otras fuentes de agua ni con las conducciones de aguas residuales, por lo que no pudo infectarse toda el agua de la ciudad. Por su parte, en el apartado anterior ya hemos comentado que los datos epidemiológicos no concuerdan con una contaminación por un hongo de los cereales ni con una deficiencia vitamínica ${ }^{48}$.

En segundo lugar, Morens y Littman (1992, p.285) analizan la posibilidad de que se tratara de una infección transmitida persona a persona. Tres son los mecanismos por los que pude diseminarse así una enfermedad: entérica (es decir, transmisión fecal-oral), por inoculación o por vía respiratoria. En cuanto a la primera forma de transmisión, los autores la desechan pues no resulta factible que se infecten de este modo miles de personas en unas pocas semanas, como nos relata Tucídides. Por su parte, la transmi- 
sión por inoculación también puede descartarse por la misma razón que la anterior, es decir, tanto si el contagio fue por vía sexual como si lo fue por una zoonosis (es decir, transmitida a partir de animales infectados), no es esperable una tasa de ataque tan alta como la que existió.

Dentro de la vía de transmisión de persona a persona, Morens y Littman (1992, p.285) analizaron la posibilidad de que se transmitiese por vía respiratoria, que concordaría mucho mejor con ese brote explosivo relatado por Tucídides. Las infecciones así transmitidas tienen una tasa de ataque y de contagiosidad altísima, no distinguen clases sociales, sexos ni edades y se asocian a situaciones de hacinamiento. Todo lo anterior concuerda con la ciudad de Atenas, lo que no lo hace es (como ya he comentado a propósito de la gripe) que las infecciones de transmisión respiratoria se extinguen con rapidez en poblaciones cerradas pues pronto dejan de existir personas susceptibles. Por el contrario, la enfermedad ateniense se prolongó durante años de manera ininterrumpida o en sucesivos brotes. Otro dato que no concuerda es, como comenta Tucídides (2.54.1), que el ejército espartano no se vio afectado a pesar de que los contactos entre ambos bandos fueron frecuentes.

Morens y Littman (1992, p.287) utilizan en su estudio un modelo matemático para determinar el tiempo en el que podría desarrollarse una infección hasta extinguirse, a partir de datos como el periodo de incubación de ésta, la cantidad de población expuesta, la densidad de población y la susceptibilidad. Así, los autores aseguran que una epidemia por el virus de la gripe se habría extinguido en nueve semanas y una epidemia por el virus del sarampión o por el virus de la viruela en unos pocos meses. Los autores (Morens y Littman, 1992, p.249) concluyen así, que una infección transmitida por vía respiratoria, que cursa de manera explosiva y se extingue con rapidez, no se adecúa a la epidemia de Atenas. Sin embargo, Littman (2009, p.462) apunta que este modo de transmisión podría cuadrar si se asociara la posibilidad de que el microorganismo perviviera en algún lugar que actuara como reservorio ${ }^{49}$.

En cuanto a la tercera posibilidad, esto es, la transmisión asociada a un reservorio insecto o animal, sí podría casar con la epidemia que estudiamos, pues este tipo de infecciones se asocia a una persistencia muy larga, así como a la posibilidad de brotes recurrentes $^{50}$ (Morens, Littman, 1992, p.292). Entre ellas podemos destacar la malaria, la peste bubónica (ya descartada anteriormente por la ausencia de su signo característico), algunas enfermedades producidas por arbovirus (como el dengue, la fiebre amarilla o la fiebre del valle del Rift) y el tifus epidémico. De todas las anteriores la única que concuerda en su curso clínico con la enfermedad ateniense es el tifus epidémico. Esta es una enfermedad típica de situaciones de guerra y hacinamiento y puede persistir en poblaciones numerosas durante periodos muy prolongados. Por otra parte, pueden aparecer recurrencias de los signos y síntomas en las personas infectadas (enfermedad de Brill-Zinsser), durante las cuales vuelven a ser infecciosas. Como he comentado en el apartado anterior, el dato clínico que no cuadra es el tipo de exantema que describe Tucídides aunque quizá pueda deberse a una descripción inexacta del mismo o a que la bacteria pueda haber cambiado a lo largo de los siglos y con ella alguna manifestación del cuadro clínico subsiguiente (Littman, 2009, p.462).

Como conclusión, son dos enfermedades las más firmes candidatas a ser la causa de la epidemia ateniense: la viruela asociada a la pervivencia del virus en algún reservorio y el tifus epidémico ${ }^{51}$, aunque ninguna de las dos case completamente con la descripción tucidídea.

\section{CONCLUSIONES}

Para Longrigg (1992, p.32) en toda la obra de Tucídides se aprecia la convicción profunda de que existe un elemento impredecible que es inherente a los asuntos humanos y que puede trastocar todo lo construido. La plaga fue ese factor imprevisto que socavó la política de Pericles ${ }^{52}$.

Una plaga ha sido el factor imprevisto que ha trastocado muchas grandes empresas. Así, Zinsser (1935, p. 6) asegura que las lanzas, espadas, flechas, pistolas e incluso la tecnología moderna han tenido mucho menos impacto en el destino de la humanidad que el piojo que transmite el tifus, la pulga de la peste o el mosquito de la fiebre amarilla. El mismo autor afirma en otro párrafo de su famoso libro que el tifus, junto con sus hermanos la peste, el cólera, la fiebre tifoidea y la disentería, han decidido más campañas militares que Julio César, Aníbal, Napoleón y todos los grandes generales de la historia. De hecho, fueron las infecciones las que allanaron el camino a los conquistadores españoles en el Nuevo Mundo, las que frenaron a los europeos en su conquista de los tró- 
picos africanos durante siglos o las que impidieron que Napoleón avanzara por Rusia. Podemos afirmar también que la epidemia que sufrió la ciudad de Atenas en el inicio de la larga guerra del Peloponeso contribuyó a la derrota de los atenienses.

Desde la concepción microbiológica de la enfermedad enunciada por Pasteur y los formulados de Koch, ambos a finales del siglo XIX, cambió la mentalidad humana y ya sólo somos capaces de entender la infección en términos microbiológicos. Ello ha provocado que hayan sido múltiples los intentos de los estudiosos por tipificar la epidemia ateniense y podemos comprobar cómo han ido variando las posibilidades diagnósticas en función de las enfermedades más prevalentes del momento. Así, las enfermedades exantemáticas virales eran la primera opción cuando la vacunación sistemática de la población aún no había conseguido reducirlas a la pequeña cifra actual, mientras que el virus Ébola no fue barajado como posibilidad hasta el año 2015 pues hasta entonces no había supuesto una amenaza para la salud humana o, mejor dicho, no había tenido repercusión mundial.

\section{NOTAS}

1 La causa de dicha guerra era clara para Tucídides: el crecimiento del poder ateniense. En el libro 1 (89-117) el historiador habla del periodo de cincuenta años que abarca desde las Guerras Médicas (479 a.C.) hasta el inicio de la Guerra del Peloponeso (431 a.C.). Este periodo, Ilamado Pentecontecia por un escoliasta (en 89.1) se caracterizó por un aumento progresivo del poder ateniense y un recelo paralelo por parte de Esparta (Hornblower, 1991, p. 133). Tras las Guerras Médicas, la victoria contra los persas exigía una continuidad de la ofensiva mantenida por la flota que controlaba el Egeo para evitar nuevas invasiones persas en las ciudades jonias. Éstas confiaron en Atenas para esta vigilancia y en el año 477 a.C. se creó en la isla de Delos una liga liderada por los atenienses. El final de las hostilidades con el imperio persa privó de sentido a la Liga de Delos, pero Atenas no quiso renunciar a ella pues la había convertido en un auténtico imperio al servicio de la democracia. Aunque son varios los sucesos que se consideran desencadenantes últimos de la Guerra, la causa determinante para la ruptura de las hostilidades fue el miedo por parte de los aliados peloponesios del desmedido poder hegemónico ateniense y su política exterior expansiva.

2 Jouanna (2005, p.3) afirma que existían puntos de contacto entre la historia y la medicina en la época clásica. Los médicos no eran ajenos al modo de pensar de los historiadores, de hecho, los médicos hipocráticos se podían considerar "historiadores de la enfermedad". Por su parte, los historiadores tenían que lidiar con enfermedades en el curso de sus relatos históricos y también utilizaban la medicina metafóricamente como un modelo para los asuntos
Así, volvemos al concepto de enfermedad y de diagnóstico como construcciones humanas fundamentalmente sociales, y vemos cómo también en épocas modernas es más habitual pensar en las entidades nosológicas más prevalentes de cada época. Podemos hacer, por tanto, una aproximación a la posible etiología de la epidemia tucidídea aunque nunca un diagnóstico preciso. Lo cual, a mi parecer, no resta interés a una revisión sobre las entidades más plausiblemente asociadas a la enfermedad ateniense como una parte del estudio sobre el elocuente relato de Tucídides.

Lo que resulta innegable es que la descripción que realizó el historiógrafo ateniense sobre la peste de Atenas es uno de los textos antiguos que se ha analizado más minuciosamente desde varias ópticas: la filología, la historia, la arqueología, la paleopatología y la medicina. Su narración ha apasionado e inspirado a muchos estudiosos a lo largo de siglos y es esperable que siga haciéndolo en generaciones venideras.

políticos. Así, el político se presentaba como un médico que iba a restaurar la "salud" de la ciudad en los momentos de crisis. Esta metáfora ha seguido vigente hasta la actualidad (recordemos al "cirujano de hierro" por el que clamaba en 1902 el regeneracionista Joaquín Costa para "extirpar" los males de España tras la Crisis del 98).

3 Como afirma Demont (2013, p.74), Tucídides es un hombre de su tiempo y como tal suscribe la relación entre anomia y pestilencia que era habitual en esta época, pero ofrece una versión revisada y racionalizada de esta dualidad. De hecho, invierte la relación causal de manera que, en su relato de la peste, la anomia va a ser causa de la enfermedad y no al contrario.

4 El término peste en medicina alude a la peste bubónica, infección por la bacteria Yersinia pestis, transmitida a los humanos por la pulga de la rata, que cursa con fiebre elevada y aparición de bubones en distintas localizaciones del cuerpo y que tiene una alta mortalidad.

5 http://dle.rae.es fecha de consulta 13-11-2017.

6 http://dle.rae.es fecha de consulta 13-11-2017.

7 Son muy interesantes los trabajos de Pino Campos y Hernández González (2008a y 2008b) sobre el significado original del vocablo griego epidemía ( $\varepsilon \pi ı \delta \eta \mu i ́ \alpha)$ como "visita" o "llegada a un lugar" y que en el ámbito de la medicina se refería a la visita del médico al paciente y viceversa (por ejemplo, los tratados hipocráticos llamados Epidemias se refieren a las visitas de unos médicos a sus pacientes y recogen una serie de casos clínicos, en ningún modo epi- 
démicos según la acepción actual). Entre los médicos

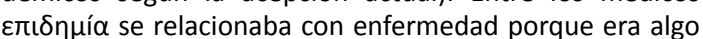
que venía desde fuera hacia dentro, que llegaba a una población. Ya en los textos hipocráticos, las enfermedades se clasificaban según su origen en dos tipos: "naturales" (enfermedades por causa natural) y "epidémicas" (enfermedades por causa de una llegada, irrupción o visita a un pueblo). Así, desde los tratados hipocráticos ya se consideraba que las enfermedades colectivas eran epidémicas porque se debían a algo extraordinario que "visitaba" a la población. En latín, la traducción literal de $\varepsilon \pi \iota \delta \eta \mu i ́ \alpha$ era visitatio, y así se aplicó desde las primeras traducciones latinas de los textos hipocráticos. El término "peste" deriva del latín pestis, sin embargo, en griego antiguo existía una palabra específica para designar esa enfermedad inesperada, contagiosa y grave que traducimos por "peste": $\lambda$ 入ıuós. La confusión entre los términos "epidemia" y "peste" se produjo seguramente por un fenómeno lingüístico (ver 2008a, p.217). Debido a una interpretación nosocéntrica, la palabra griega $\varepsilon \pi ı \delta \eta \mu i ́ \alpha$ ha pasado a las lenguas modernas en la acepción médica actual de enfermedad grave, extendida y transmisible como la peste.

8 Entre otros, A.J. Woodman, Rhetoric in Classical Historiography: Four Studies, Londres, Croom Helm, 1988 y J. Bellemore e I.L Plant, "Thucydides, Rhetoric and Plague in Athens", Athenaeum 82, 1994, pp. 385-401.

9 Lucrecio (De rerum natura VI, 1138-1286), Virgilio (Geórgicas III, 474-566), Ovidio (Metamorfosis VII, 523-613), Séneca (Edipo, 110-201), Lucano (Farsalia VI, 80-105).

10 G. Bocaccio (Decamerón).

11 Véase a modo de ejemplo, D. Defoe (Diario del año de la peste); E.A. Poe (La máscara de la muerte roja), A. Manzoni (Los novios), T. Mann (Muerte en Venecia), A. Artaud (EI teatro y la peste), A. Camus (La peste) o J. Saramago (Ensayo sobre la ceguera).

12 Cunningham (1991, p. 28) afirma que "las enfermedades infecciosas son necesaria y exclusivamente definidas por el laboratorio".

13 En los informes clínicos son habituales diagnósticos como "Sepsis clínica no confirmada microbiológicamente", que se trata con antibióticos igual que si hubiera habido un resultado positivo en el laboratorio. Podemos afirmar que la clínica del paciente "manda" sobre las pruebas de laboratorio.

14 Jouanna (2006, p.208) anota que Tucídides no muestra el mismo rigor científico cuando en el libro I (1.23) asocia la crueldad de la guerra con la violencia de desastres naturales como terremotos, eclipses, sequías, hambruna y la "enfermedad pestilente". De hecho, para Hornblower (1991, p. 317), es como si existieran dos Tucídides, de forma que el que asocia la guerra con hechos portentosos es muy distinto del que describe la peste de una forma sobria y científica.

15 Para él, la enfermedad era "contagiosa" en el sentido moderno de la palabra, aunque ese vocablo ni siquiera existiera en el mundo griego (Conrad y Wujastyk, 2000, XI).

No olvidemos que la medicina anterior a Hipócrates tenía una doble vertiente, positiva y sacra. Aceptaba un origen material de la enfermedad siempre que éste fuese cognoscible; en el resto de los casos, la causa de la enfermedad se atribuía a los dioses. Para Hipócrates las enfermedades

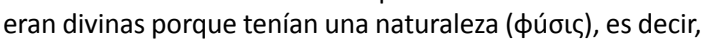
un patrón regular de origen y evolución (Laín Entralgo, 1970, p.57), pero no lo eran en el sentido de haber sido enviadas por un dios airado. Así, Hipócrates y sus seguidores, desecharon la magia y la superstición como posibles tratamientos de los padecimientos físicos de sus pacientes (Van der Eijk, 1991, p.168). Tucídides, por su parte, también intentó dar una explicación lógica a una de las hasta entonces llamadas "enfermedades divinas", fruto de la corriente novedosa del clasicismo que buscaba una explicación terrenal a los fenómenos desconcertantes.

16 Una percepción similar a la noción de contagio de Tucídides la encontramos en un discurso de defensa de un acusado por parte del orador Isócrates (Aegineticus 390, 29), pronunciado unos años antes ante un jurado en la isla de Egina. El orador defendía que en sus últimos días Trasíloco enfermo de tisis no tenía más cuidadores que un esclavo y el acusado. Los pocos amigos que se atrevieron a acercarse al enfermo temían por la vida del acusado y le instaron a irse, pues "muchos de los que tratan esa enfermedad mueren ellos mismos". Vemos que ya se conocía la posibilidad de la transmisión de una enfermedad de persona a persona. Sin embargo, los escritos hipocráticos que han llegado hasta nosotros no la mencionan, sino que consideran que las enfermedades colectivas tenían el origen en un "miasma" o exhalación insana engendrada bajo condiciones atmosféricas insalubres y que se transmitía por la respiración (Demont, 2013, p. 76; Jouanna, 2005, p. 17).

17 Diodoro Sículo (12.45.2) y Plutarco (Pericles 34) coinciden con Tucídides en su planteamiento del contagio. Podemos pensar que lo hicieron porque Tucídides era su fuente de conocimiento de la epidemia, pero no podemos asegurar que no tuvieran acceso a otras fuentes, hoy perdidas para nosotros.

18 Véase por ejemplo Epidemias I y III.

19 Cunningham (1991, p. 54) afirma que en el pasado la identidad de las enfermedades estaba constituida por sus síntomas (mientras que en el presente la identidad de las enfermedades está constituida por su agente causal).

20 De hecho, una lectura atenta de las Epidemias permite descubrir que los médicos hipocráticos otorgaron tres nombres a las regularidades en el parecido entre sí de las enfermedades individuales: $\varepsilon \hat{\delta} \delta \varepsilon\llcorner\alpha$ ( $\varepsilon i ́ \delta o \varsigma$ es el hábito biológico del enfermo, aquello en lo que se asemeja su constitución a la de muchos otros), трóro (трóroı son los modos típicos en la presentación o realización concreta de

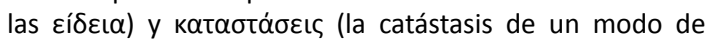
enfermar es la descripción de los síntomas que lo consti-

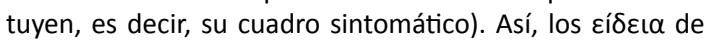
las enfermedades son las especies morbosas, los тро́то las formas clínicas o variedades típicas de las especies

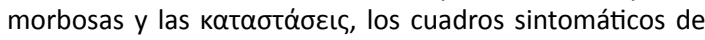
cada uno de los procesos morbosos individuales (Laín Entralgo, 1970, p. 233).

$21 \mathrm{Hp}$, Prog.1: "Que el médico se ejercite en la previsión me parece excelente. Pues si conoce de antemano y predice ante los enfermos sus padecimientos presentes, los pasa- 
dos y los futuros, y si les relata por completo incluso los síntomas que los pacientes omiten contar, logrará una mayor confianza en que conoce las dolencias de los pacientes, de manera que las personas se decidirán a encomendarse a sí mismas al médico. Y así dispondrá del mejor modo el tratamiento, al haber previsto lo que va a ocurrir a partir de la situación actual".

22 Quizá sea este interés en el pronóstico de las enfermedades el que ocasionó, según Gomme (1956, p. 149), que Tucídides, que tanto se había explayado en los motivos que desencadenaron la guerra, se limitara a describir el curso clínico de la enfermedad, sin incidir en sus posibles causas.

23 En opinión de Morgan (1994, p.204), si analizamos la descripción de Tucídides, el historiador parece estar recitando una lista de signos y síntomas "de la cabeza a los pies" a la manera de un estudiante recién ingresado en la facultad de Medicina, como si no quisiera olvidar ningún dato y para ello siguiese un orden anatómico estricto. Sin embargo, en los tratados hipocráticos se comprueba que era muy frecuente que también los médicos siguieran dicho orden en la descripción de las manifestaciones clínicas de las enfermedades.

24 Es cierto que cuando un agente infeccioso viral provoca una epidemia, suele imponerse sobre los otros virus de transmisión aérea. Lo anterior se pudo comprobar recientemente durante la pandemia de gripe de 2009 causada por el virus Influenza A (H1N1). En el otoño e invierno de ese año no se aislaron virus habituales de la época (como Parainfluenza, Rinovirus, Adenovirus...) de las secreciones respiratorias de los pacientes. Sin embargo, cuando el agente es bacteriano, no suele anular a otros agentes, es más, como afirma Zinsser (1935, p.120), durante un brote grave de una epidemia, suele haber un incremento de otras enfermedades infecciosas pues las circunstancias para su transmisión son favorables por el hacinamiento, la hambruna y la acumulación de cadáveres.

25 En opinión de Papagriorakis, Yapijakis et al (2006, p.207), la pulpa dentaria resulta el material ideal para el análisis de ADN microbiano por su buena vascularización, su durabilidad y porque es un tejido estéril en pacientes sin bacteriemia. Sin embargo, varios autores entre los que se encuentran Gilbert, Cuccui et al (2004, p.342) han puesto en duda la afirmación anterior, ya que en su opinión las capas externas de los dientes se contaminan fácilmente con material genético de su alrededor, y aunque el procesado de la muestra en el laboratorio sea muy cuidadoso, lo anterior puede llevar a resultados erróneos.

26 Hay que resaltar, por otra parte, que la falta de cereal en Atenas era un problema endémico, que se agravó por la invasión peloponesia y la guerra.

27 También concuerda el hecho que resalta Tucídides (2.51.3) de que los enfermos que sobrevivían no volvían a enfermar.

28 Por ejemplo, la epidemia de Sífilis de Nápoles de 1494; la de viruela en México en 1530 (con una tasa de mortalidad del 50\%) o la de sarampión en las islas Fiji en 1875 (con una tasa de mortalidad del 25\%).

29 Los virus y las bacterias evolucionan mediante mutación y selección y es cierto que muchos de ellos han perdido vi- rulencia con el paso del tiempo (Poole, Holladay, 1979, p.284). También es cierto que otros microorganismos han evolucionado hacia una mayor infectividad o se han vuelto más difíciles de tratar por el desarrollo de resistencias a los antimicrobianos (Kliegman, Behrman et al, 2009, p.1111).

30 Son dos las únicas enfermedades erradicadas por la acción del hombre: la viruela en 1980 y la peste bovina (que atacaba al ganado, no al hombre) en 2011. No sabemos si pudo haberse erradicado alguna más de forma natural, sin que el hombre interviniera en ello.

31 A propósito de lo anterior, Longmuir et al (1985, p.1027) desarrollaron una teoría que implicaba como agentes conjuntos de la epidemia de Atenas al virus de la gripe y al Staphylococcus y al cuadro resultante lo denominaron síndrome de Tucídides, cuya repercusión en medicina fue inexistente, y fue ampliamente rebatido por Morens y Littman (1994, p.627).

32 La rata es el principal reservorio de la bacteria, que se transmite al hombre mediante las pulgas. Es habitual la creencia de que la rata no apareció en Europa hasta el siglo XII, cuando fue traída accidentalmente por los cruzados en su vuelta al hogar. No existía un término específico para rata en griego, aunque sí para roedor. Lo que resulta curioso es que la rata sí existiera en esa época en Egipto, que era la principal fuente de abastecimiento de grano para Grecia (Longrigg, 1980, p.213).

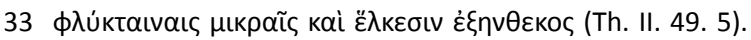

34 También concuerdan la diarrea y las complicaciones intestinales, aunque no el resto de los datos, como hemos visto en el apartado anterior a propósito del hallazgo de ADN de la bacteria Salmonella enteritidis, causante de la fiebre tifoidea, en la pulpa dentaria de piezas halladas en la fosa común excavada en el Cerámico.

35 Sin embargo, la tasa de mortalidad del sarampión no es tan alta como la de la enfermedad tucidídea.

36 El artículo de Kazanjian (2015, p.963) defiende la posibilidad de que el causante de la epidemia fuera el virus Ébola. En contra de lo anterior podemos apuntar que Tucídides no se refiere en ningún momento a un exantema hemorrágico ni a hemorragias en las mucosas, así como que la primera infección por el virus Ébola se describió en 1976. El autor apunta que quizá la infección fuera prevalente en la Antigüedad, después pasara siglos sin dar manifestaciones y volviera a presentarse a finales del siglo pasado, pero resulta poco plausible.

37 La epidemia de gripe de 1918, aunque causó millones de muertos en todo el mundo, tenía una tasa de mortalidad inferior al $1 \%$. Los fallecimientos fueron tan numerosos porque la prevalencia de la infección fue altísima (Durack, Littman et al 2000, p.392).

38 "Al invierno siguiente, la peste atacó a Atenas por segunda vez pues, aunque no había cesado del todo en ningún momento, sí que había habido una mitigación. Esta segunda epidemia duró no menos de un año, mientras que la primera fueron dos" (Th 3.87)

39 La viruela tenía una tasa de mortalidad del 30\%. De los enfermos que sobrevivían, a su vez el 30\% quedaba ciego por las cicatrices que quedaban en la córnea. 
40 Sí es cierto que existían dos tipos de viruela, maior y minor (que correspondían a dos virus distintos). La primera tenía una mortalidad y un porcentaje de complicaciones mucho mayores que la segunda. La epidemia ateniense pudo tratarse de una viruela minor que hubiese dejado pocas señales cutáneas en los supervivientes, sin embargo, lo anterior no concuerda con la virulencia de la enfermedad descrita por Tucídides.

41 Conocemos con seguridad que existían piojos en Grecia pues Aristófanes bromea sobre ellos en la Paz (739).

42 Las manifestaciones clínicas típicas del tifus epidémico son fiebre, cefalea intensa, dolor abdominal y exantema. Menos frecuentemente aparecen escalofríos, mialgias, artralgias, anorexia, tos, mareo, náuseas, vómitos y diarrea, así como manifestaciones del sistema nervioso central como delirio, coma y convulsiones. Como complicaciones tardías pueden aparecer amnesia, ceguera y gangrena periférica (Kliegman, Behrman et al, 2009, p.1297).

43 La fiebre en el tifus epidémico suele durar unos 10-14 días y durante la segunda semana de la enfermedad los pacientes suelen estar estuporosos, delirantes o incluso en coma (Kliegman, Behrman et al, 2009, 1298). Los enfermos atenienses, por su parte, tenían insomnio y les costaba trabajo descansar (Th 2.49.3).

44 La epidemia también afectó a otras ciudades griegas, así como a otras zonas del Mediterráneo oriental. "En el Ática comenzó a aparecer por primera vez la famosa peste, de la que se decía que había atacado con anterioridad en muchos otros lugares, como en Lemnos y en otros parajes" (Th 2.47). Tito Livio (4.20-21; 4.25.3-4; 4.30.8-10) describe en su obra una epidemia que ocurrió en Roma en 433 y 428 a.C.

No obstante, podemos preguntarnos si podemos estar seguros de que se trate de la misma epidemia. No sería raro que en un contexto de guerra diversas enfermedades causaran estragos en distintos puntos del Mediterráneo.

45 Esta densidad de población tan alta es comparable a la de la actual ciudad de Nueva York. Pero si pensamos que en

\section{BIBLIOGRAFÍA}

Arrizabalaga, Jon (1999), "Medical Causes of Death in Preindustrial Europe: Some Historiographical Considerations", Journal of the History of Medicine, 54/2, p. 241-260.

Arrizabalaga, Jon (2002), "Problematizing retrospective Diagnosis in the History of Disease", Asclepio, 54 (1), p. 51-70.

Artaud, Antonin, El teatro y su doble Barcelona, Edhasa, 2011.

Baziotopoulou-Valavani, Effie (2002), "A Mass Burial from the Cemetery of Kerameikos". En: Stamatopoulou, Maria and Yeroulanou, Marina (eds.), Excavating Classical Culture: Recent Archaeological Discoveries in Greece. Studies in Classical Archaeology I, Oxford, Beazley Archive, pp.187-201.

Bellemore, J., Plant, I.L. (1994), "Thucydides, Rhetoric and Plague in Athens", Athenaeum 82, 1994, pp. 385-401.

Bocaccio, Giovanni, Decamerón, Madrid, Cátedra, 2007.
Atenas no existían edificaciones en altura, la densidad es aún mayor, para Morens y Littman (1994, p.623), comparable a la de un campo de concentración.

46 La tasa de ataque de una enfermedad se calcula dividiendo el número de personas que han desarrollado la enfermedad entre el número de personas expuestas en un determinado periodo de tiempo y multiplicando el resultado por cien.

47 La tasa de mortalidad de una enfermedad se calcula dividiendo el número de personas que han muerto por una enfermedad entre el número de personas que han enfermado y multiplicando el resultado por cien.

48 Al desechar la infección a partir de una fuente común, Morens y Littman (1992, p.284) consideran que pueden descartarse algunas de las enfermedades propuestas por otros autores como cólera, disentería, shigelosis, fiebre tifoidea, ergotismo o escorbuto.

49 Por ejemplo, el virus de la viruela puede sobrevivir durante meses en las secreciones secas de los enfermos que hayan quedado en ropas, sábanas o incluso en fardos de algodón. Otra posibilidad es que el virus de la viruela fuera transportado a campo abierto por alguna persona enferma y que persistiera una cadena de transmisión de persona a persona muy lenta, a causa de la baja densidad de población de las zonas rurales (Littman, 2009, p.462).

50 Entre éstas, se pueden descartar algunas de las propuestas porque en ellas la infección humana es accidental en el curso de la transmisión zoonótica, por ejemplo, muermo, leptospirosis, rabia, psitacosis y tularemia. Otras se pueden descartar porque nunca cursado en forma de epidemias, como el ántrax (Morens, Littman, 1992, p.296).

51 El tifus ha sido compañero inseparable del hombre en todas las situaciones de guerra, hambre y pobreza en que éste se ha encontrado.

52 Pericles murió en 429 a.C. víctima de la peste ateniense y con él su forma de entender la democracia.

Camus, Albert, La peste, Barcelona, Edhasa, 2002.

Conrad, Lawrence I., Wujastyk, Dominik (2000), Contagion. Perspectives from Pre-Modern Societies, Aldershot, Ashgate, p. XI.

Cunningham, Andrew (1991), "La transformación de la peste. El laboratorio y la identidad de las enfermedades infecciosas", Dynamis, 11, p. 27-71.

Cunningham, Andrew (2002), "Identifying Disease in the Past: Cutting the Gordian Knot", Asclepio, 54 (1), p. 13-34.

Defoe, Daniel, Diario del año de la peste, Madrid, Impedimenta, 2006.

Demont, Paul (2013), "The Causes of the Athenian Plague and Thucydides". En: Tsakmakis, A., Tamiolaki, M. (eds.), Thucy- 
dides between History and Literature, Berlín/Boston, De Gruyter, pp. 73-87.

Diodoro de Sicilia, Biblioteca histórica, libros IX-XII (traductor: Juan José Torres Esbarranch), Madrid, Gredos, 2006.

Durack, David, Littman, Robert, Benítez, Michael, Mackowiak, Philip (2000), "Hellenic Holocaust: A Historical Clinico-Pathologic Conference", The American Journal of Medicine, 109, pp.391-397.

Gilbert, Thomas, Cuccui J., White, W., Lynnerup, N. et al (2004), "Absence of Yersinia pestis specific DNA in human teeth from five European excavations of putative plague victims", Microbiology, 150 (2), pp.341-354.

Gomme, Arnold W. (1956), A Historical Commentary on Thucydides, II, Oxford, Oxford University Press.

Hope, Valerie M., Marshall, Eireann (eds.) (2000), Death and Disease in the Ancient City, London, New York, Routledge.

Hornblower, Simon (1991), A Commentary on Thucydides, I, Oxford, Oxford University Press.

Horstmanshoff, Manfred H.F.J. (1990), “The Ancient Physician: Craftsman or Scientist?", The Journal of the History of Medicine and Allied Sciences, 45, pp.176-197.

Jouanna, Jacques (2005), "Cause and Crisis in Historians and Medical Writers of the Classical Period". En: Van Der Eijk, P.H., Hippocrates in Context, Leiden, Boston, Brill, pp. 3-27.

Jouanna, Jacques (2006), "Famine et pestilence dans I'Antiquité grecque: un jeu de mots sur limos/loimos". En: Jouanna, J; Leclant, J.; Zink, M.(eds.), L'Homme Face aux Calamités Naturelles dans IÁntiquité et au Moyen Âge. Cahiers de la villa de "Kérylos", 17, París, pp. 197-219.

Kazanjian, Powel (2015), "Ebola in Antiquity?", Clinical Infectious Diseases, 16, September, pp.963-968.

Kliegman, Robert, Behrman, Richard, Jenson, Hal, Stanton, Bonita (eds.) (2009), Nelson. Tratado de Pediatría, (18a Edición), Barcelona, Elsevier.

Kosak, Jennifer Clarke (2000), "Fifth-century Greek ideas on city and disease". En: Hope, Valerie M., Marshall Eireann (eds.), Death and Disease in the Ancient City, London, New York, Routledge, pp. 35-54.

Laín Entralgo, Pedro (1949), La historia clínica hipocrática (www.cervantesvirtual.com).

Laín Entralgo, Pedro (1970), La medicina hipocrática, Madrid, Revista de Occidente.

Leven, Karl Heinz (2004), "At times these ancient facts seem to lie before me like a patient on a hospital bed-Retrospective diagnosis and ancient medical history". En Hortsmanshoff, H.F.J. et al (eds.), Magic and Rationality in Ancient Near Eastern and Graeco-Roman Medicine, Leiden, Brill, p. 369-386 (citado en pág. 11).

Littman, Robert J., Littman, Michael L. (1969), "The Athenian Plague: Smallpox", Transactions and Proceedings of the American Philological Association, 100, pp.261-275.
Littman, Robert J. (2009), "The Plague of Athens: Epidemiology and Paleopathology", Mount Sinai Journal of Medicine, 76, pp.456-467.

Longmuir, Alexander et al (1985), "The Thucydides Syndrome. A New Hypothesis for the Cause of the Plague of Athens", The New England Journal of Medicine, 313 (16), pp.1027-1030.

Longrigg, James (1980), "The Great Plague of Athens", History of Science, XVIII, pp.209-225.

Longrigg, James (1992), "Epidemic, ideas and classical Athenian society". En Ranger, Terence, and Slack, Paul (eds.), Epidemics and Ideas: Essays on the Historical Perception of Pestilence, Cambridge, Cambridge University Press, pp. 21-44.

Lucano, Farsalia o Guerra Civil (trad. Jesús Bartolomé Gómez) VI, 80-105, Madrid, Cátedra, 2003.

Lucrecio, De la naturaleza de las cosas (trad. Miguel Castillo Bejarano) VI, 1138-1286, Madrid, Alianza, 2016.

Mann, Thomas, Muerte en Venecia, Barcelona, Edhasa, 2010.

Manzoni, Alessandro, Los novios, Madrid, Cátedra, 2015.

Mitchell-Boyask, Robin (2009), "Plague and theatre in Ancient Athens", The Lancet, 373, 1, p. 374-375.

Morens, David M., Littman, Robert J. (1992), "Epidemiology of the Plague of Athens", Transactions of the American Philological Association, 122, pp.271-304.

Morens, David M., Littman, Robert J. (1994), "Thucydides Syndrome" Reconsidered: New Thoughts on the "Plague of Athens", American Journal of Epidemiology, 140 (7), pp.621-629.

Morgan, Thomas E. (1994), "Plague or Poetry? Thucydides on the Epidemics al Athens", Transactions of the American Philological Association, 124, pp.197-209.

Muramoto, Osamu (2014), "Retrospective diagnosis of a famous historical figure: ontological, epistemic and ethical considerations", Philosophy, Ethics and Humanities in Medicine, 9, 10, p. 1-17.

Nutton, Vivian (2004), Ancient Medicine, New York, London, Routledge.

Ovidio, Metamorfosis (trad. Consuelo Álvarez y Rosa M. Iglesias) VII, 523-613, Madrid, Cátedra, 2005.

Papagriogorakis, Manolis, Yapijakis, Christos, Synodinos, Philippos, Baziotopoulou-Valavani, Effie (2006), "DNA examination of ancient dental pulp incriminates thyphoid fever as a probable cause of the Plague of Athens", International Journal of Infectious Diseases, 10, pp.206-214.

Papagriogorakis, Manolis (2007) "Ancient typhoid epidemic reveals possible ancestral strain of Salmonella enterica serovar Thyphi", Infection, Genetic and Evolution, 7, pp.126-127.

Plutarco, Vidas paralelas: Pericles-Fabio Máximo (traductor: Bernardo Perea Morales), Madrid, Gredos, 2010. 
Pino Campos, Luis Miguel, Hernández González, Justo Pedro (2008a), "En torno al significado original del vocablo griego epidemía y su identificación con el latino pestis", Dynamis 28, pp. 199-215.

Pino Campos, Luis Miguel, Hernández González, Justo Pedro (2008b), "Los conceptos de peste y epidemia: semántica y lexicografía", Revista de Filología de la Universidad de La Laguna, 26, pp. 191-204.

Poe, Edgar Allan, La máscara de la muerte roja, Madrid, Ediciones Fénix, 2015.

Poole, J.C., Holladay, A. James (1979), "Thucydides and the Plague of Athens", The Classical Quarterly, 29 (2), pp.282-300.

Rechenauer, Georg (2011), "Polis nosousa: Politics and Disease in Thucydides-the Case of the Plague". En: Rechenauer, G., Vassiliki P. (eds.), Thucydides-a violent teacher? Goettingen, V\&R unipress, pp. 241-260.

Retief, Francoise Pieter, Cilliers, Lynette (1998), "The Epidemic of Athens 430-426 B.C.", South African Medical Journal, 88 (1), pp.50-53.

Romilly, Jaqueline (Trad.) (1991), Thucydide. La guerre du Péloponnèse, París, Les Belles Lettres.
Saramago, José, Ensayo sobre la ceguera, Madrid, Alfaguara, 1996.

Séneca, Edipo (trad. Jesús Luque Moreno) 110-201, Madrid, Gredos, 1980.

Tito Livio, Historia de Roma desde su fundación IV-VII (traductor: José Antonio Villar Vidal), Madrid, Gredos, 1990.

Tucídides, Historia de la Guerra del Peloponeso, (trad. Juan José Torres Esbarranch), Madrid, Gredos, 2008.

Van der Eijk, Philip (1991) “Airs, Waters, Places" and "On the Sacred Disease": Two Different Religiosities?", Hermes 119 (2), pp. 168-176.

Virgilio, Geórgicas (trad. Tomás de la Ascensión Recio García) III, 474-566, Madrid, Gredos, 2010.

Wilson, Adrian (2000), "On the history of disease-concepts: the case of pleurisy", History of Science, 38, p. 271-319.

Woodman, A.J. (1988), Rhetoric in Classical Historiography: Four Studies, Londres, Croom Helm.

Zinsser, Hans (1935), Rats, Lice and History, New Jersey, Toronto, New York, London, Bantam Books. 